\title{
O diário de bordo e suas potencialidades pedagógicas
}

\author{
LUCAS LARCHER
}

Lucas Larcher é Artista-Docente-Pesquisador e Diretor de Artes Cênicas da Universidade Federal do Espírito Santo (UFES). Doutorando em Artes pela Universidade Estadual Paulista (UNESP), Mestre em Artes pela Universidade Federal de Uberlândia (UFU), possui graduação em Teatro pela mesma instituição, - com bolsa sanduíche no exterior (CNPq-CAPES) na Universidade de Évora (UÉ), em Portugal -, e em Artes Visuais pelo Centro Universitário Claretiano de Batatais (CEUCLAR).

AFILIAÇÃO - Universidade Federal do Espírito Santo (UFES) - Espírito Santo - Brasil http://buscatextual.cnpq.br/buscatextual/visualizacv.do?id=K4401659P4 


\section{- RESUMO}

Este artigo tem como objetivo reconhecer e explicitar algumas das possíveis potencialidades pedagógicas trazidas pela elaboração de diários de bordo em situações de criação e de ensino-aprendizagem no âmbito das Artes, em especial das Artes Cênicas. Para isso, foi realizada uma revisão bibliográfica sobre o diário de bordo, que apontou para a identificação deste como uma espécie de criação de natureza diversa a do processo artístico documentado, como um catalisador para as constantes (re)criações do sujeito - artista e autor -, fazendo-o refletir a partir de suas experiências, como um instrumento de avaliação, permitindo orientações e acompanhamento de percursos, e como uma fonte para pesquisas e/ou práticas pedagógicas. Aspectos estes que colaboram para o entendimento de que a criação de uma obra artística e/ou o ensino-aprendizagem em Artes se configuram como uma complexa trama que entrelaça a Arte e a Educação.

\section{PALAVRAS-CHAVE}

Diário de bordo; potencialidades pedagógicas; artes cênicas.

\section{ABSTRACT}

This article aims to recognize and explain some of the possible pedagogical potentialities brought by the elaboration of logbooks in creation situations and teaching-learning in the Arts, especially in the Performing Arts. For this, a bibliographical review was carried out on the logbook, which pointed to its identification like a kind of creation of a different nature from that the documented artistic process, like a catalyst for the constant subject's (re)creations - artist and author -, making him reflect from his experiences, like an evaluation tool, allowing guidance and accompaniment of the track, and as a source for research and / or pedagogical practices. These aspects collaborate to the understanding that the creation in an artistic work and / or teaching-learning in Arts are configured as a complex network that intertwines Art and Education.

\section{KEYWORDS}

Logbooks; pedagogical potentialities; performing arts 


\section{O diário de bordo ${ }^{1}$}

Registrar os acontecimentos do cotidiano vem sendo uma constante na história da humanidade, mesmo que inconscientemente. Das escrituras nas cavernas às postagens em redes sociais, vários têm sido os modos encontrados pelo homem, ao longo dos tempos, para documentar ou deixar rastros do vivido. Com os artistas isto não é diferente. De natureza fragmentária, os registros de uma criação podem oferecer pistas sobre a gênese de uma obra de arte e os meandros de sua configuração, ajudando-nos a compreender os pensamentos dos criadores, sem desconectá-los das circunstâncias temporais, espaciais, sociais e econômicas em que estão inseridos, e que se relacionam com a obra concebida.

Neste contexto, tais registros podem ser chamados de documentos do processo de criação, uma vez que constituem um conjunto de vestígios concretos gerados, intencionalmente ou não, pelos envolvidos na elaboração de uma obra de arte, revelando e desvelando seus bastidores. Ou, ainda, uma tentativa de dar forma-conteúdo ou materialidade a acontecimentos de maneira a levá-los para a posteridade. Desenhos, fotografias, assim como textos verbais são alguns dos possíveis exemplos destes materiais.

Conhecida por seus estudos no campo da Crítica Genética, ou Crítica de Processo, como prefere nomear, Cecília Almeida Salles, em seu livro "Gesto Inacabado - Processo de criação artística" (2009), refere-se à importância dos documentos gerados em meio a processos criativos em diversas manifestações. Compostos por diferentes linguagens, estes registros dos artistas, quando acessíveis, revelam a riqueza e a complexidade da atividade criativa e/ou artística, oferecendo aos interessados indícios acerca dos procedimentos de configuração do objeto ou do processo artístico. Nas palavras da autora:

Os documentos de processo são, portanto, registros materiais do processo criador. São relatos temporais de uma gênese que agem como índices do percurso criativo. Estamos conscientes de que não temos acesso direto ao fenômeno mental que os registros materializam, mas estes podem ser considerados a forma física através da qual esse fenômeno se manifesta. Não temos, portanto, o processo de criação em mãos mas apenas alguns índices desse processo. São vestígios vistos como testemunho material de uma criação em processo. (SALLES, 2009, p. 21)

Originado das anotações sobre acontecimentos em trajetos de navegações, o diário de bordo se configura não apenas como um instrumento náutico para expedições marítimas, mas também como a nomenclatura de uma espécie complexa que reúne conjuntos de documentos de processos de pesquisa ${ }^{2}$ e criação. Esta coleção, que se apresenta sob diferentes formatos, revela fatos, buscas, descobertas e indagações acerca de criações e da vida íntima de seus autores, sendo uma espé-

\footnotetext{
1 Este texto é uma adaptação do trabalho de conclusão de curso em Artes Visuais do autor, pelo Centro Universitário Claretiano de Batatais, em 2018.

2 Embora a criação contenha a pesquisa, neste texto, optamos por evidenciar as duas atividades, no intuito de referenciar a utilização de diários de bordo, ou cadernetas de anotações, por outros profissionais que não os artistas, como, por exemplo, os etnógrafos.
} 
cie de ombro amigo de artistas. Nomes como dos pintores Paul Klee e Frida Kahlo, dos escritores Fiodor Dostoievvski e Guimarães Rosa, e dos encenadores Constantin Stanislavski e Bertold Brecht são possíveis exemplos que surgem quando nos referimos às anotações diárias feitas ao longo de elaborações artísticas, e/ou como uma forma de prestação de contas a si mesmo.

Marina Marcondes Machado, em seu artigo "O diário de bordo como ferramenta fenomenológica para pesquisador em Artes cênicas" (2002), destaca a importância dos diários para os artistas inseridos no universo acadêmico das Artes Cênicas. Compartilhando pormenores do seu processo de pesquisa no mestrado, a autora elabora um breve conceito para esta espécie de agrupamento de registros do qual estamos falando. Para ela:

[...] a expressão Diário de Bordo refere-se a uma das etapas do trabaIho do pesquisador acadêmico em Artes Cênicas que realiza sua pesquisa processualmente (metodologia work in process). O Diário de Bordo é a compilação de todas as anotações que um encenador-criador faz durante a escritura, montagem e encenação do espetáculo sobre o qual, futuramente, sua dissertação ou tese vai tematizar e discutir. (MACHADO, 2002, p. 260)

Ampliando o conceito trazido por Machado, podemos dizer que o diário de bordo seria, então, pelo menos no âmbito das Artes Cênicas, a compilação de todas as anotações, de natureza verbal ou não, que um artista faz durante seus processos de criação, os quais abarcam, muitas vezes, situações de ensino-aprendizagem. Sendo, assim, um recurso que auxilia no desenvolvimento da autonomia de um artista (seja ele discente ou docente), e que, também, reflete as particularidades ou as individualidades de cada autor, revelando percepções individuais e/ou coletivas de diferentes instâncias da criação em foco.

O diário de bordo, como recurso envolto nos processos de criação e de ensino-aprendizagem em Artes Cênicas, pode apresentar grande potencial pedagógico, nos diferentes contextos educacionais: formal, não-formal e informal. Implicando a superação da ideia de transferência de conhecimento em processos de ensinoaprendizagem, o diário de bordo configura-se como uma espécie de instrumento metodológico ${ }^{3}$, que guarda expressões técnicas e expressivas e revelações de natureza subjetiva de seu autor, mas também reflete (sobre) práticas artísticas e pedagógicas.

Este texto justifica-se, portanto, sob o ponto de vista temático, pela necessidade de aprofundamento em questões relacionadas aos diversos recursos metodológicos presentes nos processos de criação e de ensino-aprendizagem em Artes, mais especificamente em Artes Cênicas. Sendo foco de estudo de um número ainda restrito de pesquisadores da área, o diário de bordo tem sido pouco abordado em seu caráter potencial em diferentes contextos educacionais, de maneira a problematizar verticalmente algumas questões intrínsecas a sua prática, o que pode

\footnotetext{
${ }^{3}$ Acerca da concepção do diário de bordo como recurso metodológico, deve-se destacar que, no início do século XX, o pedagogo Célestin Freinet promoveu uma interessante pesquisa sobre o que ele denominou de "livro da vida". Esta variante do diário de bordo elaborada por Freinet nada mais era que um caderno no qual crianças registravam acontecimentos do dia a dia em classes escolares.
} 
contribuir para uma maior clareza na elaboração, na observação, na reflexão e na interpretação sobre/dos mesmos.

O objetivo geral deste trabalho é reconhecer e explicitar, mesmo que em linhas gerais, algumas possíveis potencialidades pedagógicas trazidas pela elaboração do diário de bordo em situações de criação e de ensino-aprendizagem em Artes Cênicas. Para isso, a metodologia utilizada para a elaboração do presente artigo foi a revisão bibliográfica acerca do tema abordado, procurando identificar nas referências consultadas como diferentes autores, - que elaboraram reflexões sobre o assunto em diferentes contextos -, articulam e produzem conhecimento sobre o foco de estudo. E, ainda, apontam, mesmo que não explicitamente, qualidades promissoras do mesmo.

Consultando algumas referências bibliográficas sobre o tema, é possível reconhecer certas recorrências no que diz respeito às possibilidades trazidas pela elaboração de diários de bordo em situações de criação e de ensino-aprendizagem, independente do contexto em que estas se dêem. Para além de importante aliado no registro e na documentação de fatos, o diário de bordo também pode ser visto como uma espécie de criação de natureza diversa à do processo documentado, como um catalisador para as constantes (re)criações do sujeito, fazendo-o refletir a partir de suas experiências ${ }^{4}$, como um instrumento de avaliação, e até mesmo, como um fonte para pesquisas - conforme Salles aponta - e/ou práticas pedagógicas. Aspectos destrinchados a seguir.

\section{O diário como criação de natureza diversa}

Éric Le Coguiec, em seu artigo "Ficção, diário de campo e pesquisa-criação" (2016), ao se referir ao diário de bordo a partir da nomenclatura diário de campo, frisa que este suporte sempre mescla em sua constituição realidade e ficção, atuando esta última "não como objeto de estudo, mas como objeto praticado pelo pesquisador" (COGUIEC, 2016, p.32). Sendo um recurso que documenta o vivido e/ou o imaginado, o diário de bordo tem a memória como elemento que o constitui, e que possibilita ao mesmo não ser apenas um registro de dados ordinários, ou fatos, mas também uma espécie de reordenação do acontecido e/ou imaginado, exprimindo as reflexões subjetivas desencadeadas pelas vivências e pela imaginação de um artista, que se torna autor.

No texto supracitado, embora não seja a intenção primeira de Coguiec, somos impelidos a reconhecer o diário de bordo, como uma espécie de criação, obra de arte, que, no âmbito das Artes Cênicas, é elaborada a partir de uma materialidade outra, que não os corpos dos intérpretes e o espaço que estes se expressam. Portadores de uma materialidade própria, os registros contidos no diário são arquitetados "na linguagem mais acessível no momento, que ficam à espera de uma futura tradução" (SALLES, 2009, p. 120), possibilitando o exercício da experimentação da criação, ou de nuances não-cênicas.

Permitindo que a linguagem cênica, efêmera por natureza, possa ser docu-

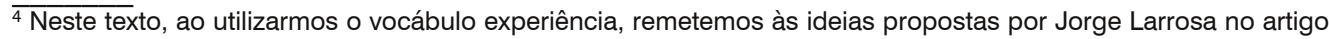
"Notas sobre a experiência e o saber de experiência" (2002). Segundo o autor, a experiência seria aquilo que realmente atravessa e acontece ao sujeito.
} 
mentada em seu processo de elaboração, e não apenas como produto acabado como em registros fílmicos de apresentações -, o diário de bordo se estrutura por meio de matérias não convencionais à artesania da cena. Sobretudo por imagens estáticas (na forma de desenhos e/ou fotografias) e conteúdos verbais, construindo narrativas (lineares ou não) ou escritas de outras naturezas.

Salles aponta para a operação destacada acima. Chamada de tradução intersemiótica, a transposição de um sistema de signos para outro é um processo de (re)criação ousado e complexo. Isto é: à medida que desloca signos (significados e significantes) de uma determinada conformação estética para outra, faz confluir dois discursos simultâneos, além de poder combinar em um mesmo meio comunicativo diferentes sistemas de signos que podem criar estruturas de diversas ordens, e revelar aspectos sobre as linguagens articuladas. Temos, então, que:

Nos documentos de processo são encontrados resíduos de diversas linguagens. Os artistas não fazem seus registros, necessariamente, na linguagem na qual a obra se concretizará. Ao acompanhar diferentes processos, observa-se na intimidade da criação um contínuo movimento tradutório. Trata-se, portanto, de um movimento de tradução intersemiótica, que, aqui, significa conversões, ocorridas ao longo do percurso criador, de uma linguagem para outra: percepção visual se transforma em palavras; palavras surgem como diagramas, para depois voltarem a ser palavras, por exemplo. (SALLES, 2009, p. 119)

Este movimento de (re)criação pode ser observado, por exemplo, nos trechos retirados do diário de bordo de Ana Cristina Colla e apresentados no livro que reproduz sua dissertação de mestrado: "Da minha janela eu vejo... Relato de uma trajetória pessoal de pesquisa no LUME" (2006). Neste caso, a autora materializava sob a forma do discurso verbal, em um diário de bordo, suas experiências como intérprete no começo da trajetória do LUME, Centro de Pesquisa Teatral, vinculado à UNICAMP - Universidade Estadual de Campinas. Por meio de anotações pontuais, como sobre os locais de encontro para as práticas teatrais, ou de suas sensações e percepções, Colla opera um movimento tradutório, no qual a escrita sobre/ de si reconstitui o vivido, e dá pistas ou repercute na (re)criação do sujeito, com suas facetas de artista e autor, como abordado adiante.

\section{O diário e a (re)criação do sujeito}

Outra potencialidade pedagógica que podemos apontar a partir da elaboração de diários de bordo é a possibilidade que esta traz para a tomada de consciência das experiências vividas pelo artista e autor, e consequentemente, a (re)criação do sujeito e de seu entorno. Se, nas Artes Cênicas, a matéria primeira utilizada nos processos criativos é o próprio corpo, que nada mais é do que o próprio intérprete, o diálogo entre criação e criador se dá na operação de (trans)formação ou configuração de (si como) uma obra de arte. O diário seria uma espécie de catalisador deste processo, possibilitando o desvelamento de uma metamorfose que, por ve- 
zes, ocorre internamente no criador e/ou artista.

Deste modo, podemos dizer que elaborar um diário é fazer emergir a subjetividade de quem o cria, uma vez que, para além de registrar fatos objetivos, o artista e autor, por meio de pensamentos, dúvidas e angústias, pratica um tipo de exposição de seu eu, através de reflexões que lançam luzes e podem ajudar a compreender questões que, antes embrenhado nos meandros do processo de criação e de ensino-aprendizagem, não conseguia descortinar com facilidade.

Nesta espécie de guia de reflexão sobre a prática cênica: o diário de bordo, seu autor pratica um relativo afastamento do processo que registra. À medida que observa sua criação, registrando a elaboração de uma obra, o artista e autor promove uma modificação e/ou uma reconstrução do objeto artístico, pois deixa de o conceber simplesmente com um olhar primeiro, completamente envolvido em sua confecção. Registrando seu trabalho em outra linguagem, o artista e autor é requisitado a se tornar um primeiro crítico do processo que vivencia.

Além disso, é preciso deixar claro que, nos processos criativos que envolvem situações de ensino-aprendizagem, o registro na forma de diário de bordo pode contribuir para a compreensão das elaborações de discentes pelo docente. Este, apoiando-se na concretude do diário, terá maiores possibilidades de compreensão dos entremeios de uma dada criação, e, poderá interferir nas criações dos discentes, indagando, propondo intervenções ou mudanças, e consequentemente ampliando as reflexões dos aprendizes, deflagrando processos cognitivos e sensíveis que pressupõem o estabelecimento de diálogo entre criação e criador.

Embora Marcondes, no texto citado, entenda que o diário de bordo nas Artes Cênicas apresenta anotações de caráter pré-reflexivo, neste artigo, consideramos que o próprio ato de registro traga consigo o exercício da reflexão, e consequentemente, de (re)criação do sujeito que conjuga as facetas de artista e autor. Afinal, não é à toa que Clarice Lispector formula em sua crônica "Sobre escrever" (1999, p. 54) que: "ao escrever, eu me dou as mais inesperadas surpresas. É na hora de escrever que muitas vezes fico consciente de coisas, das quais, sendo inconsciente, eu antes não sabia que sabia". Ou seja: o ato da escrita - ou, mais amplamente, do registro - pode revelar o caminho e a transformação do sujeito a partir de uma experiência, no momento em que se efetiva.

\section{O diário como instrumento de avaliação}

Também é possível encontrarmos pistas acerca de outra potencialidade pedagógica a partir da utilização do diário de bordo em contextos educacionais, agora no artigo de Alberto Roiphe. Em "O relato de experiência como narrativa" (2015), Roiphe nos atenta para elementos que podem ser importantes na elaboração de narrativas que podem estar contidos nos diários, tanto por docentes, tanto por discentes, no contexto formal de ensino, mais especificamente a escola básica. Entretanto, o que chama atenção em seu texto é a perspectiva de avaliação levantada pelo autor. Para ele, os relatos de experiência e/ou narrativas, que podem estar contidos no diário de bordo, adquirem e/ou atribuem a este recurso o status de possível instrumento avaliativo, proporcionando que o docente acompanhe o percurso ou processo de criação e de ensino-aprendizagem dos estudantes, ou de si 
mesmo, enquanto professor.

Apoiando-nos nas palavras de Roiphe, e versando acerca da figura do discente, podemos dizer que a prática de elaboração de diários de bordo pode proporcionar aos estudantes a sistematização própria ou (re)elaboração dos conteúdos abordados durante os processos de criação e de ensino-aprendizagem, sejam eles: factuais, conceituais, procedimentais e atitudinais. E, com isto, a abertura para as subjetividades intrínsecas aos processos de criação e de ensino-aprendizagem, muitas vezes reveladas por meio do exercício do registro, nas entrelinhas dos discursos, sejam eles de natureza verbal e/ou não-verbal.

Já sobre a figura do docente, Roiphe (2015, n.p.) diz que: "é por meio de um relato de experiências, portanto, que o professor pode se tornar, à medida que narra, consciente de seu ato didático também como um ato de criação", e, ainda, que: "por meio de um relato de experiências é possível conhecer a concepção de ensino de um professor, suas práticas pedagógicas, sua metodologia de ensino". Deste modo, poderíamos dizer que o diário de bordo atua como um confessor, que delata questões epistemológicas e metodológicas de práticas pedagógicas, e, com isto, colabora para a clareza destas à medida que se dão, a partir de registros objetivos e/ou sensíveis e individuais sobre uma experiência coletiva. A saber: uma aula.

Apesar de os escritos de Roiphe se referirem a um contexto específico, as considerações apresentadas podem ser redimensionadas para outras situações de criação e de ensino-aprendizagem. Se compreendermos a avaliação como uma espécie de atividade orientadora e de acompanhamento dos percursos, que podem ser (re)orientados durante o "caminhar", é possível perceber que o diário de bordo, além de registrar a construção de um conhecimento e/ou de uma obra de arte, permite que o processo de construção de um conhecimento e/ou obra de arte possa ser elucidado, e, caso seja necessário, redirecionado, oferecendo pistas de pontos nevrálgicos.

\section{O diário como fonte}

Por fim, é preciso destacar que o diário de bordo pode se configurar como uma fonte para pesquisas (acadêmicas e/ou artísticas) e/ou práticas pedagógicas, sejam estas do próprio autor, ou de terceiro. Conforme elucida Salles, em sua obra já citada algumas vezes neste artigo, registros, como os que compõem os diários de bordo, podem servir como estímulos ou provocadores para pesquisas e/ou práticas pedagógicas em diferentes contextos. O que não se trata de uma grande novidade, já que muitas dissertações e teses de profissionais docentes versam a partir, justamente, de suas experiências documentadas em cadernos de registros ou diários de bordo.

A título de exemplo sobre a utilização de diários de bordo como material propulsor para uma investigação, destacamos as pesquisas acadêmicas de Colla como supracitado - e de Machado, publicada sob a forma do livro "Cacos da Infância: Teatro da solidão compartilhada" (2004). Além delas, também frisamos a pesquisa de mestrado do próprio autor deste artigo, que, assim como a de Machado, versa sobre aspectos do Teatro Infantojuvenil da atualidade, narrando a experiência do artista e autor na elaboração e nas apresentações do espetáculo "O Mensageiro 
do Rei", em Uberlândia - MG, e tem como fonte as memórias deste, materializadas ou não na forma de diário de bordo, assim como os diários de bordo elaborados por outros integrantes da equipe de criação do espetáculo. O título deste trabalho é: "Inventariando O Mensageiro do Rei - reflexões e discussões acerca do teatro Infantojuvenil” (2016).

Com relação ao diário de bordo como fonte para práticas pedagógicas, um exemplo pertinente é o trecho retirado do livro "Os melhores anos de muitas vidas: 50 anos de Tablado" (2001), no qual a autora Martha Rosman narra que, informalmente, acompanhava as atividades docentes de sua mestra Maria Clara Machado, quando esta era responsável pelas aulas de improvisação livre na Escola livre d'O Tablado. Neste episódio, podemos reconhecer, então, a riqueza de um diário de bordo à medida que como fonte se desdobra em conhecimento, exercendo sua função primeira: registrar ou documentar, que em espiral origina uma nova prática pedagógica. Rosman, em uma feliz nota, assim diz:

[...] Clara dava aulas de uma forma maravilhosa. E eu, que não sou boba nem nada, tinha meu caderno de apontamentos. Anotava tudo, sobretudo os exercícios bem elaborados que fazíamos em cena. Primeiro ela dava o tema. Lá fora no pátio nos reuníamos em pequenos grupos, ensaiávamos rapidamente e corríamos para o palco. Às vezes, representávamos exercícios maravilhosos, verdadeiras peças em um ato. Alguns mudos, outros falados, e eu anotando até as correções e críticas. Isto aconteceu durante anos: Clara foi minha única mestra.

Um dia ela me perguntou: "O que é que você tanto escreve?". Respondi: "Tudo e todas as suas aulas." Ela pediu para ler e me convidou para fazermos um livro juntas. Foi assim que iniciamos 100 Jogos Dramáticos numa fase diferente que passei no Tablado. [...]. (ROSMAN, 2001, p. 11)

Levando em consideração o trecho exposto, percebemos que os registros feitos pela autora, a partir de sua vivência, puderam se configurar como um rico material, que, além de servir como fonte para sua própria prática pedagógica, originou outra textualidade, que compartilha uma prática artística e/ou pedagógica observada e/ou vivenciada. Como uma espécie de derivação do diário de bordo de Rosman, o livro "100 Jogos Dramáticos" (2001) possui sua gênese nos registros da artista e autora que, por meio da observação da própria prática teatral e da reflexão sobre a mesma, viu seus registros originarem um material que ultrapassou o caráter puramente subjetivo, a ponto de ser publicizado.

Neste ponto, cabe destacar ainda que, embora não saibamos se o texto que compõe o livro de Rosman e sua mestra possua trechos do diário da primeira, em alguns escritos surgidos a partir de pesquisas e/ou práticas pedagógicas que se utilizam do diário de bordo como fonte, fragmentos deste são reproduzidos. Assim, os textos de campo integram a trama a qual damos o nome de texto final, sendo este mais burilado, sem, contudo, perder o frescor e a espontaneidade presente nos 
registros feitos ao longo de processos de criação e/ou de ensino-aprendizagem. A dissertação de Colla (2006) é um exemplo de tal configuração.

\section{Considerações finais}

No intuito de finalizarmos as considerações apresentadas na tessitura deste artigo, retomamos as ideias expostas em seu início. Por meio da consulta a textos de autores que se dedicaram a produzir e/ou refletir sobre o diário de bordo, foi possível depreender de contextos e exemplos específicos questões empíricas que ajudam a esboçar primeiros lampejos sobre o mesmo, destacando diferentes olhares para o tema desta escrita. Partindo de sua origem histórica e de sua função primeira - registrar e servir de ombro amigo a seus autores -, percebemos que a usabilidade do diário de bordo no contexto artístico, em especial o das Artes Cênicas, expande-se para além da dinâmica estabelecida entre processos de criação artística e vida pessoal do criador e autor.

Ao pensarmos o diário de bordo como um recurso envolto nos processos de criação e de ensino-aprendizagem em Artes Cênicas, pudemos reconhecer algumas das possíveis potencialidades pedagógicas trazidas por seu uso em distintas modalidades educacionais, através de um aprofundamento em questões que emergem na/da prática de sua elaboração. Mesclando realidade e ficção, este agrupamento de documentos de processos criativos se configura materialmente de modo diverso às elaborações estéticas relacionadas à cena, e, por meio das linguagens verbal e não verbal, apresentam vestígios, índices e/ou rastros de uma dada criação.

Concebido também como criação artística, o diário de bordo possibilita que o artista e autor exercite a observação de si mesmo e/ou de um processo que vivencia, compartilhado sob a forma de registros (confidenciais ou não) uma espécie de reflexão sobre suas experiências. Deste modo, experiência, registro e reflexão são justapostos formando uma unicidade que dá sustentação para uma tomada de consciência do criador e autor sobre o que faz, e, assim, uma (re)criação do sujeito, que se modifica à medida que cria, aprende e ensina.

Além disso, ao colaborar com o acompanhamento de um percurso de criação e de ensino-aprendizagem, o diário de bordo pode vir a ser um instrumento avaliativo. Retomando as ideias apresentadas por Roiphe, ao falar sobre a elaboração de narrativas para o compartilhamento de experiências, as linhas e entrelinhas de um diário de bordo colaboram para que docentes e discentes tenham uma clareza sobre suas trajetórias de criação e ensino-aprendizagem. $\mathrm{E}$, deste modo, a construção de um conhecimento que se caracteriza pela autonomia, e se funda na própria experiência do artista e autor.

Configurando-se como fonte para pesquisas (de cunho acadêmico e/ou artístico) e/ou práticas pedagógicas em diferentes contextos, o diário de bordo tem evidenciada sua riqueza - enquanto registro de experiências - e seu poder de comunicação para com o outro. Neste sentido, partindo dos exemplos apresentados neste artigo, como mote provocador para investigações, o diário de bordo se configura como um recurso que pode ainda se reverberar em uma nova textualidade. E, com isso, uma nova criação... 
Por fim, cabe aqui destacar que todas as considerações feitas ao longo deste texto revelam as diferentes facetas de um mesmo recurso metodológico utilizado nas criações e nos processos de ensino-aprendizagem em Artes. E mais: colaboram para o entendimento de que a criação de uma obra artística não se configura como um processo de simples inspiração apenas, sem tentativas, erros, acasos e outras interferências sofridas pela subjetividade do criador e por questões do contexto em que o mesmo encontra-se inserido. Em síntese: o diário de bordo destrinchado em suas potencialidades pedagógicas nos lembra que a Arte e a Educação estão entrelaçadas em uma complexa trama.

\section{REFERÊNCIAS}

COGUIEC, Éric Le. Ficção, diário de campo e pesquisa-criação. Trad. Mônica Fagundes Dantas. Revista Cena, Porto Alegre, no 20, p. 28-38, 2016. Disponível em: $<$ http://seer.ufrgs.br/index.php/cena/article/view/68331/39010>. Acesso em: 18 de março de 2017.

COLLA, Ana Cristina. Da minha janela eu vejo... Relato de uma trajetória pessoal de pesquisa no LUME. São Paulo: Hucitec, 2006.

LARCHER, Lucas. Inventariando O Mensageiro do Rei - reflexões e discussões acerca do Teatro Infantojuvenil. Dissertação de Mestrado em Artes, Instituto de Artes da Universidade Federal de Uberlândia (UFU), Uberlândia, 2016.

LARROSA, Jorge. Notas sobre a experiência e o saber de experiência. Revista Brasileira de Educação, 2002, no 19 , p. 20-28.

LISPECTOR, Clarice. Sobre escrever. In: A descoberta do mundo: crônicas. Rio de Janeiro:

Rocco, 1999. p. 54.

MACHADO, Maria Clara; ROSMAN, Martha. 100 Jogos Dramáticos. São Paulo: Agir, 2001.

MACHADO, Marina Marcondes. O Diário de Bordo como ferramenta fenomenológica para o pesquisador em artes cênicas. Revista Sala Preta, São Paulo, v.2, p. 260-263, 2002. Disponível em: <http://www.revistas.usp.br/salapreta/article/view/57101/60089>. Acesso em: 18 de março de 2017.

MACHADO, Marina Marcondes. Cacos de Infância: Teatro da solidão compartilhada. São Paulo: FAPESP/Annablume, 2004.

ROIPHE, Alberto. O relato de experiências como narrativa. Boletim Arte na Escola, Edição 75, Março e Abril de 2015. Disponível em: <http://artenaescola.org.br/boletim/materia.php?id=74787>. Acesso em: 18 de março de 2017.

ROSMAN, Martha. Os melhores anos de muitas vidas: 50 anos de Tablado. Rio de janeiro: Agir, 2001.

SALLES, Cecília Almeida. Gesto Inacabado - Processo de criação artística. 4⿳ạ ed. São Paulo: FAPESP - Annablume, 2009.

ouvirouver Uberlândia v. 15 n. 1 p. 100-111 jan.|jun. 2019 
Recebido em 31/05/2018 - Aprovado em 16/04/2019

Como citar:

LARCHER, L. (2019). O diário de bordo e suas potencialidades pedagógicas. OuvirOUver, 15(2), 100-111. https://doi.org/10.14393/OUV24-v15n1a2019-7

(c) () (-) A revista ouvirOUver está licenciada com uma Licença Creative EY NC Commons Atribuição-NãoComercial 4.0 Internacional. 